\title{
Association of Schools of Public Health Annual Report
}

\author{
Alfred Sommer, MD, MHS \\ Dean, Johns Hopkins University School of Public Health \\ Chair, ASPH Executive Committee
}

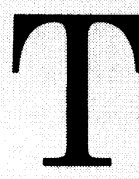

he number and strength of America's accredited schools of public health have grown substantially in recent years and, in response, so too have the initiatives and goals of the Association of Schools of Public Health (ASPH). This first written annual report to its members is one of many changes made to the Association's by-laws and approved by the schools on July 20, 2000.

Recent ASPH initiatives include:

- A far more focused legislative agenda. ASPH now targets a few, critical legislative initiatives of high priority to its members, particularly initiatives for which there are few other champions. These include enhancing the strength and number of CDC's Prevention Research Centers and Centers for Public Health Preparedness, increased funding for CDC's Prevention Research Initiative, and strong support for expansion in the number of HRSA Public Health Training Centers and traineeships

- Regular, periodic "summits" with the leadership of CDC, NIH, HRSA, and other federal agencies to ensure mutually supportive approaches to the development and administration of new programs that advance the public's health.

- A major new collaborative initiative, in partnership with the American Public Health Association (APHA), to explore "credentialing" public health professionals, as a means of enhancing the visibility and stature of the profession and raising the quality of the nation's public health workforce.

- Revisiting the process and rationale by which schools of public health are accredited, in order to ensure that schools are encouraged to enhance, in the most effective ways possible, the quality of academic public health, its core research and educational missions, and its ability to best prepare students for rapidly changing career opportunities.

- A vigorous review of the purpose, educational content, and competencies expected of those awarded the MPH degree. The career goals of those pursuing this degree vary almost as widely as the content and organization of degree programs offered by accredited schools.

- A strategic and innovative look at our "brand name." Does the term "public health" adequately convey to the populace and our potential supporters what our schools, or our graduates, actually do? Public opinion polls repeatedly demonstrate tremendous support for what "public health" does, but almost no recognition of, or support for, the term itself. Defining our "scope of practice" is the first step in educating the public and gaining insight into how best to describe what we do and develop "brand recognition."

- With growth in our collective strength, and concomitant expan-

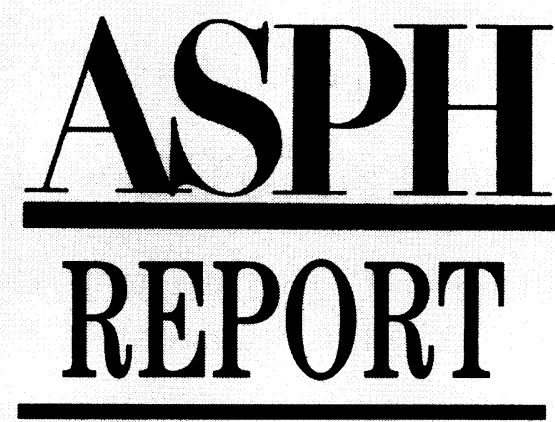

sion of our collective initiatives, it became necessary to reorganize ASPH to more efficiently and effectively serve its national role and better represent its constituent schools. ASPH created the full-time staff position of "President," to be filled by a prominent individual representing academic public health. The elected ASPH leadership position, formerly titled President, will now be titled Chair.

I'm personally delighted with the changes ASPH has undergone over the past few years, and even more so with the growth in prominence and strength of the schools that made these changes both possible and necessary. I'm equally delighted that we were able to recruit an outstanding public health professional to fill the new, full-time "presidential" position: Harrison Spencer, MD, MPH, past dean of the Tulane School of Public Health and Tropical Medicine and, most recently, the London School of Hygiene and Tropical Medicine. He has already brought enthusiasm and energy to his new position and to the association as a whole.

On another note, Susan Scrimshaw, $\mathrm{PhD}$, Dean of the School of Public Health at University of Illinois at Chicago, will begin her term as the ASPH Chair on January 1, 2001. The Association will be in capable hands. Our collective future could not look brighter. 


\section{Credentialing the Public Health Workforce-Its Time Has Arrived}

\section{Douglas S. Lloyd MD, MPH, FACPM HRSA Senior Scholar at ASPH}

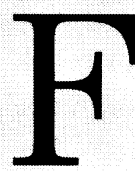

ew reports have had the impact on the field of public health of the Institute of Medicine's 1988 report on The Future of Public Health.

While public health activities were in "disarray," the report's authors felt a new approach of assessment, policy development, and assurance would help develop a new vision for public health.

While the IOM painted its picture with a broad brush, and targeted all of society for public health's missteps, this report sparked a period of reflection and introspection in those who teach and apply the knowledge and tools to improve the nation's health.

After a decade of mulling it over, the leadership of the public health community has coalesced its energies around the education, training, and activities of its workforce. $A$ beehive of activity has been directed toward defining the essential public health services, proposing new performance standards, designing new curricula with redefined competencies, and determining new teaching methods via distance education.

Meanwhile, both anecdotal and survey information have disclosed that many senior public health positions, especially those at the leadership level, may be filled by those with no training in public health. Public health agencies may not have a majority of their staff with any public health training at all. And senior health leaders often cite at least an introductory course in public health as a priority for their agency.

\section{The APHA-ASPH} Task Force on Credentialing At the annual joint meeting of ASPH and APHA in November, the organizations' leaderships agreed that the public health workforce lacks definition, appreciation, and visibility. To the executive committee participants, there was one thing that could change that: development of a discernible, visible, and organized profession. Since that meeting, a task force has been meeting to consider the rather formidable agenda of developing and advancing a profession for the field of public health.

To the task force the advantages appear clear. Professionalism would benefit public health enormously:

- Increase the recognition of public health's members

- Raise the visibility of the public health workforce

- Ensure high standards to better serve the health of the public

- Promote the profession's perspective of focusing on the population and prevention.

(See: Sommer A, Akhter MN. It's Time We Became a Profession. Am J Public Health 2000;90:845-6.)

\section{Views of the Stakeholders}

A series of meetings have been held with the major stakeholders in public health. The practice community at the federal, state, and local levels has debated the issues and responses from their constituencies. From the federal government, CDC and HRSA have described their recent work on the credentials issue and their assessment of its worth to the field of public health.
Several points of agreement have been noted.

- The groups in attendance continue to remain in favor of proceeding to developing a credentialing process for the public health workforce.

- There is widespread agreement on the need to enhance the stature of public health practitioners in the community and general agreement on moving ahead to firmly establish competencies for public health.

- The credentialing process can create a skilled, learned professional for community public health work.

- A credentialing process must recognize the importance of the practice of public health.

- The process of credentialing those in public health must not be seen as exclusionary of the valuable jobs carried out by other public health workers who are not credentialed.

\section{The Work Ahead}

The work of the past several months has resulted in agreement in the public health leadership community to proceed with the credentialing process. The original task force created by the APHA and ASPH has endorsed credentialing as a way of raising the standards and quality in the workforce and believe that it is time to establish a detailed approach to how credentialing should be instituted.

Just as public health competencies and distance education are seen as tools to enhance the abilities of the workforce, and in fact dominate the agenda of many meetings, a new attitude has emerged in the leadership of America's public health community. The acceptance of a form of credentials for the workforce appears near. 


\section{ASPH Initiatives with CDC}

Michael Gemmell, CAE Executive Director, ASPH

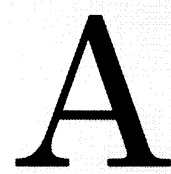

SPH has a long history of collaboration with CDC, notwithstanding a historic cooperative agreement that was established in 1981 and continues to be a viable mechanism for research and training partnerships between CDC and schools of public health. These activities include a total of over $\mathbf{4 0 0}$ research projects awarded to schools of public health, and 1,352 students to date having participated in the internship and fellowship programs with CDC.

Last January, the ASPH executive committee traveled to $\mathrm{CDC}$ and met with Jeff Koplan, CDC Director, and most of the agency leaders of the CDC centers, institutes, and offices. Major areas of discussion included current center programs and budgetary priorities for each of the $\mathrm{C} / \mathrm{I} / \mathrm{Os}$. The following are some of the principal themes that were highlighted:

Jim Marks, Director, NCCDPHP, discussed the center's interest in promoting and conducting research that encourages the translation of knowledge into practice, evaluation, and dissemination for primary focal areas of NCCDPHP, such as cancer, diabetes, arthritis, CVD, and reproductive health, among others.

Ron Valdiserri, Deputy Director, NCHSTP, discussed the center's focus on HIV/AIDs, STDs, and TB, and stressed that research on HIV/AIDs is still at the forefront of the center's priorities.

Dick Jackson, Director, NCEH, reaffirmed his long-standing advocacy and leadership for programs that address the environmental health problems facing women and children.
ASPH deans agreed to assist his center in marshalling support on Capitol Hill.

Ed Baker, Director, PHPPO, discussed the office's interest in public health workforce training, with specific reference to CDC's graduate certificate programs, distance learning activities, continuing education programs, and accreditation for public health professionals.

Jim Hughes, Director, NCID, stressed the center's focus on preparedness for emerging infectious diseases, and the center's development of emerging infections programs (EIPS) and epidemiology and laboratory capacity programs (ELCs) throughout the country.

After considering the cross-section of CDC programs and priorities, the ASPH executive committee met with Jeff and his senior staff to begin the process of talking about how we can work together in the future. The discussion centered on the three major themes of the meeting. 1) training and workforce development, 2) extramural research at $\mathrm{CDC}$, and 3) ASPH legislative activities supporting CDC.

Dean Clark discussed the following three elements of ASPH's focus on public health workforce development: reexamining the core competencies of the MPH curriculum to ensure that core curriculum addresses such areas as computer-based technologies, ethical and moral sciences, diverse community populations, policy formation, and also integration of the use of qualitative and quantitative methodology, in addition to other core skills; reaching individuals who need or want to be trained in public health (i.e., practitioners in the field ) through distance learning programs, continuing education, graduate certificate programs, and certification of public health work- ers; and training students and public health professionals in global health.

Ed Baker moderated the meeting between the deans, C/L/Os, and CDC senior staffers, and agreed that these were key areas for the $\mathrm{CDC}$, and that the two groups should work together to develop a joint curriculum for core competencies, develop student and faculty practicum opportunities in global health, and assess the workforce training efforts of ASPH and the CDC.

Dean Sommer introduced the discussion of extramural research programs at the CDC. Dean Sommer talked about two components necessary for a strong extramural research program: 1) a vigorous investigatorinitiated research program, and 2) a funding timespan greater than one year for projects. Both CDC and ASPH participants affirmed the need for increased investigator research that is closely linked to the community. Several ASPH deans commented on the value of the currently funded Prevention Research Centers program at $\mathrm{CDC}$, which encourages and requires investigators to be involved with the community and state/local health departments.

Finally, Dean Scrimshaw briefed CDC officials on ASPH's Capitol Hill priorities for FY 2001. ASPH is committed to helping $\mathrm{CDC}$ develop a unique image that transforms $\mathrm{CDC}$ as the nation's premier prevention agency as well as encouraging Congress to support extramural research and workforce training.

The meetings were very productive and resulted in expressions of mutual cooperation and respect. Both CDC and ASPH principals agreed to make this an annual event between the ASPH executive committee and CDC senior staff. The schools of public health are looking forward to a bright future of further collaboration and partnering with CDC. 


\section{ASPH Accreditation Project}

Michel A. Ibrahim, MD

University of North Carolina at Chapel Hill

$\mathrm{I}$ 1946, APHA became the first accrediting body of schools of public health. The Council on Education for Public Health (CEPH) was jointly formed by APHA and ASPH in 1974 , assuming the responsibility of accrediting schools of public health. Now, it is time to re-examine the existing accreditation process to see if it still meets the schools' needs.

In November 1999, Dean Sommer, as President of ASPH, appointed a committee to enlighten member schools about accreditation. The charge to the committee is to provide answers to three questions: (1) What is accreditation about? (2) Why do schools of public health need it? (3) What are the options for obtaining it?

The committee interviewed individuals experienced in accreditation to obtain additional information and to identify a consultant who would help the committee in discharging its responsibilities. Both goals were achieved, and the three questions were answered.

\section{What is accreditation about?}

Accreditation can be defined as a voluntary, nongovernmental, and peerreviewed process that identifies a school as maintaining certain standards and thus allows the school to market itself as one that upholds these standards. The role of the Department of Education is to recognize, but not to approve, accrediting agencies, which establish their own standards in order to receive such recognition.

Voluntary self-evaluation is inherent in traditional American values and philosophy and is rooted in the belief that self-government is the best means of achieving quality in a democracy. This philosophy and practice have pro- vided institutions of higher learning with a good measure of independence from national and state governments.

\section{Why do schools of public health need it?}

Why does a school of public health need accreditation separate from the university, which is accredited by a regional accrediting body? Regional associations of colleges and schools accredit the total institution, but they do not comprehensively look at professional schools. This has led professional schools to establish separate accreditation processes. (The opposite may also be true-that because professional schools seek their own accreditation, they are not generally covered in the university's accreditation.)

Another reason for seeking accreditation has to do with a program's eligibility for federal funds. In 1952, with the passage of the GI Bill, the federal government wanted to ensure that benefits were directed to accredited schools. An accrediting agency is apparently eligible for recognition by the Department of Education only if its accreditation is required in enabling institutions or programs to become eligible for receiving federal funds, including Title IV funding.

The federal funding issue has become even more important as a result of ASPH's long-standing policy of promoting rulemaking that specifies that only accredited schools of public health should be eligible for certain federal benefits.

\section{What are the options for obtaining it?}

Several options may be proposed for further consideration: One obvious option is to continue accreditation by CEPH, which has many strong and attractive features, not the least of which is its considerable experience. Even so, improvements might be instituted to make the organization better understood and valued. These include careful selection of council members and site visitors, promotion of an attitude of collegiality, review of the content and appropriateness of the criteria and especially of the core curriculum, and review and clarification of the basis for the number of years awarded to a school when accredited.

Another option is to create a new organization devoted exclusively to accrediting schools of public health. A variant on this theme is to "split" CEPH into two units, one for accrediting programs and a second for accrediting schools.

A third option is to develop an accreditation process based on the same principles by which colleges and universities are accredited-that is, to treat a school of public health as a "minicollege." In this case, the focus would be on the core programmatic offering, such as the MPH degree. This strategy would leave the assessment of the quality of doctoral and specialized master's programs to other evaluative mechanisms in a manner similar to that of professional schools being evaluated separately.

This accreditation project has provided background information and outlined several options. The deans may want to revisit this issue and decide on the best course of action.

Acknonvledgement: I would like to express my profound thanks to the advisory committee: Deans Beasley, Clark, Glantz, Mahan (co-chair), Penhoet, Rosenfield, and Sommer (Michel Ibrahim served as chair); the project consultant, Sherril Gelmon; and ASPH staff Mike Gemmell, Rita Kelliher, Liz Weist, and Geri Aglipay. Documents related to this project are obtainable from Geri Aglipay of ASPH at <gsa@asph.org>. 